\title{
REPRESENTASI BUDAYA JAWA PADA FILM ANIMASI "KNIGHT KRIS"
}

\author{
Arjuna Bangsawan \\ Institut Informatika Indonesia, Surabaya \\ arjuna@ikado.ac.id
}

\begin{abstract}
Abstrak
Knight Kris merupakan film animasi yang dirilis pada tahun 2017 bergenre fantasi, namun dalam latar cerita, penokohan dan tema yang diangkat mengandung unsur budaya Jawa. Fokus permasalahan dari penelitian ini adalah bagaimana tanda-tanda budaya Jawa direpresentasikan dalam film animasi Knight Kris, dan bagaimana makna yang terkandung dalam representasi budaya Jawa tersebut. Pendekatan penelitian kualitatif, tinjauan pustaka yang digunakan adalah film sebagai teks budaya, budaya Jawa, dan semiotika. Representasi budaya Jawa dalam film ini dibedah menggunakan semiotika model Peirce dan kerangka analisis film dari Fiske. Hasil penelitian menunjukkan bahwa unsur-unsur budaya Jawa dalam film animasi Knight Kris direpresentasikan melalui adegan, penokohan karakter, setting, dan musik latar. Selain itu, representasi budaya Jawa tentang tata paugeraning urip juga ditemukan pada film ini. Knight Kris juga dapat digunakan sebagai media pembelajaran karakter kepada siswa untuk mengenalkan etos Jawa dan nilai keluhuran.
\end{abstract}

Kata kunci: film animasi, semiotika, representasi, budaya Jawa, Knight Kris

\begin{abstract}
Knight Kris is an animated movie released in 2017 in fantasy genre. However, in the setting of the story, the characterization and the theme contain of Javanese cultural elements. The focus in this study is how the signs of Javanese culture were represented in Knight Kris animated movie and what are the meanings of it. The qualitative approach and the literature review used were movie as cultural texts, Javanese culture, and semiotics. The representation of Javanese culture in this movie was analyzed using Peirce's semiotic model and movie analysis framework from Fiske. The results show that Javanese cultural elements in this movie were represented through scenes, characterizations, setting, and background music. Besides that, the representation of Javanese culture about tata paugeraning urip (a way to preserve life) was found as well in this movie. Knight Kris
\end{abstract}


could also be used as media for character learning to introduce ethos and noble values to students.

Key words: animation movie, semiotic, representation, Javanese culture, Knight Kris

\section{PENDAHULUAN}

Film sebagai salah satu media massa yang diproduksi untuk mengkomunikasikan sebuah pesan, informasi, dan hiburan yang ingin disampaikan oleh sutradara kepada khalayak. Penyampaian pesan melalui film adalah cara yang mudah dan cukup efektif agar penonton bisa mengetahui informasi yang ingin disampaikan. Keberadaan film dimanfaatkan untuk mensosialisasikan budaya, politik, pendidikan, keindahan alam, dan pergaulan. Film juga berperan sebagai pembangunan ideologi untuk meningkatkan nilai-nilai moral atau mitos yang diinginkan, sebagai teks psikologis masyarakat mengenai suatu hal yang menarik atau menegangkan, sebagai bagian dari budaya yang merepresentasikan citra (image) tertentu, serta sebagai teks visual yang menawarkan level pemahaman dan pemaknaan yang bersifat kompleks.

Membicarakan isi cerita tidak bisa dilepaskan dari pembicaraan tentang pesan. Pesan dan simbol yang digambarkan baik tersirat atau tersurat dalam film memiliki peranan yang besar. Ketika seseorang melihat sebuah film, maka pesan (message) yang disampaikan oleh film tersebut secara tidak langsung akan berperan dalam pembentukan persepsi seseorang terhadap maksud pesan dalam film (Sobur, 2003:147).

Film sebagai media massa elektronik yang bersifat audio-visual memiliki keunggulan dibanding media lain yaitu mampu untuk melakukan sebuah manipulasi grafis dengan penanganan konstruksi teknik artifisial yang sangat kompleks. Hal ini pada dasarnya berarti turut mempengaruhi konstruksi dan makna pesan dalam proses produksi dan reproduksi budaya sebuah film. Sehingga dalam setiap representasi yang ditampilkan akan selalu membawa gagasan mengenai posisi sosial, pengalaman, maupun kelompok tertentu (Purwasito, 2003:137-138).

Film dapat dijadikan sebagai salah satu media pembelajaran melalui komunikasi visual. Simbol-simbol yang dimunculkan dalam film berfungsi untuk 
menyampaikan pesan (Gunarsa, 2003:40). Unsur tanda dalam sebuah film dapat dianalisis melalui kajian semiotika. Semiotik mempelajari sistem-sistem, aturanaturan, konvensi-konvensi yang memungkinkan tanda-tanda tersebut mempunyai arti. Setiap tanda yang ditayangkan dalam film merupakan bentuk perubahan dari pendeskripsian pesan. Lambang-lambang yang disampaikan dalam film merupakan representasi dari realitas. Sebagai representasi dari realitas, film mampu membentuk dan menghadirkan kembali realitas berdasarkan kode-kode, konvensikonvensi dan ideologi dari kebudayaannya (Sobur, 2009:128).

Knight Kris merupakan film animasi yang ceritanya diangkat dari kisah pewayangan, yang umumnya lebih dikenal di Jawa. Deddy Corbuzier selaku produser juga mengatakan bahwa film ini sarat akan nilai budaya Indonesia. Isi dan cerita film Knight Kris sangat kental akan nuansa Indonesia. Menghadirkan tokoh pewayangan, kemudian ada keris dari Indonesia, serta candi, yang banyak dijumpai di Indonesia.

Setiap film dikemas untuk menyampaikan pesan kepada penonton atau konsumen melalui tanda. Stimulus yang disampaikan produsen melalui kemasan film menghasilkan respon yang berbeda-beda dari konsumennya. Hal tersebut menimbulkan pertanyaan apakah para konsumen film dapat menangkap pesan dari produsen film, ataukah hanya menonton dan mengingat yang menarik namun pesan yang sebenarnya tidak tersampaikan. Apakah penonton menyadari adanya unsur budaya Jawa yang dikonsepkan dalam film animasi karya anak Indonesia Knight Kris. Oleh karena itu analisis terhadap representasi film animasi Knight Kris patut dilakukan sebagai usaha untuk melihat bagaimana tampilan budaya Jawa

Melalui analisis tanda, penelitian ini berupaya untuk mendeskripsikan representasi budaya Jawa dalam film aniamsi Knght Kris. Penggunaan dialog, properti, ekspresi, karakter dapat mencerminkan semua itu. Hal tersebut menjadi latar belakang penulis untuk meneliti tentang Representasi Budaya Jawa pada Film Animasi Knight Kris (Analisis Semiotika Charles Sanders Peirce). Film animasi Knight Kris memiliki peluang besar menjadi salah satu media pendukung pembelajaran tentang budaya Jawa. 


\section{KAJIAN TEORI}

\section{Animasi}

Animasi berasal dari bahasa Latin, anima, yang artinya jiwa, hidup, nyawa dan semangat. Animasi adalah gambar dua dimensi yang seolah olah bergerak. Animasi ialah suatu seni untuk memanipulasi gambar menjadi seolah-olah hidup dan bergerak, yang terdiri dari animasi dua dimensi dan tiga dimensi. Animasi pada awalnya hanya berupa potongan-potongan gambar ilustrasi atau fotografi yang kemudian digerakkan sehingga menjadi seolah-olah hidup. Animasi dapat dikatakan sebagai simulasi pergerakan yang dibuat dengan menampilkan gambargambar berurutan atau frames (Prakosa, 2010:38).

\section{Representasi}

Representasi merujuk pada proses dimana suatu peristiwa disampaikan dengan komunikasi, kata-kata, bunyi, citra, atau kombinasinya. Secara ringkas representasi adalah produksi makna melalui bahasa. Penggunaan bahasa (simbolsimbol dan tanda tertulis, lisan atau gambar) dapat mengungkapkan pemikiran, konsep, dan ide-ide tentang situasi. Representasi merupakan proses penggunaan tanda yang menghubungkan, menggambarkan, memotret, atau mereproduksi sesuatu yang dilihat, diindra, dibayangkan, atau dirasakan dalam bentuk fisik tertentu (Danesi, 2010:24).

\section{Budaya Jawa}

Mengkaji budaya Jawa tidak akan terlepas dari pembahasan Etnologi Jawa, yaitu ilmu yang mempelajari perbandingan budaya Jawa, dari sisi historis, sosiologi, psikologis, dan sisi pandang yang lain (Endaswara,2015:1). Dapat dikatakan sebagai budaya Jawa bila hal tersebut sering dilakukan di Jawa dan merupakan bagian dari adat atau warisan nenek moyang. Etnologi Jawa membahas perbedaan pola pada masyarakat saat ini, diantaranya; adat istiadat perkawinan, struktur kekerabatan, sistem politik dan ekonomi, agama, cerita-cerita rakyat, kesenian dan musik. Kebudayaan terdiri dari simbol-simbol, gagasan, serta nilainilai dari hasil karya tindakan manusia. Sehingga manusia berpikir, berperasaan 
dan juga bersikap melalui ungkapan-ungkapan simbolis. Kebudayaan yang terdiri dari gagasan, nilai, dan simbol sebagai hasil karya manusia membuat identitas yang disebut sebagai makhluk simbol.

\section{Semiotika}

Charles Sanders Peirce menekankan pentingnya makna tanda bagi kehidupan manusia dengan mengatakan bahwa tanda merupakan instrumen utama manusia dalam menggunakan rasionya. Manusia berfikir dengan sarana tanda. Melalui penggunan tanda, manusia berinteraksi dengan manusia lainnya dan untuk memahami lingkungannya. Bagi Peirce prinsip mendasar sifat tanda adalah sifat representatif dan interpretatif. Sifat representatif tanda berarti tanda merupakan sesuatu yang lain sedangkan sifat interpretatif artinya tanda tersebut memberikan peluang bagi interpretasi bergantung pada pemakai dan penerimanya. Dalam konteks ini, Peirce memandang bahwa proses pemaknaan (signifikasi) menjadi penting karena manusia memberikan makna pada realitas yang ditemuinya (Rusmana, 2014:107).

\section{METODE PENELITIAN}

Representasi Budaya Jawa pada Film Animasi Knight Kris (Analisis Semiotika Charles Sanders Peirce) merupakan sebuah penelitian kualitatif yang akan disajikan secara deskriptif interpretatif. Scene dalam film Animasi Knight Kris akan dianalisis menggunakan pendekatan semiotika. Sumber data pada penelitian Representasi Budaya Jawa pada Film Animasi Knight Kris (Analisis Semiotika Charles Sanders Peirce) diperoleh dari dua bagian:

1. Sumber data primer yaitu data yang berasal dari scene film animasi Knight Kris yang mengandung simbol yang berhubungan dengan budaya Jawa.

2. Sumber data sekunder yaitu data yang diperoleh dari pustaka atau media internet yang sesuai dengan penelitian. 


\section{HASIL DAN PEMBAHASAN}

Knight Kris merupakan film animasi (3D) tiga dimensi yang menjadikan keris (Kris) sebagai fokus jalan cerita. Film animasi tersebut diproduksi oleh Viva Fantasia Animation Indonesia dan diproduseri oleh Deddy Corbuzier. Film animasi Knight Kris yang ditayangkan di bioskop pada 23 November 2017 dan berbiaya produksi 18 miliar ini berdurasi 104 menit serta melalui proses produksi selama dua tahun.

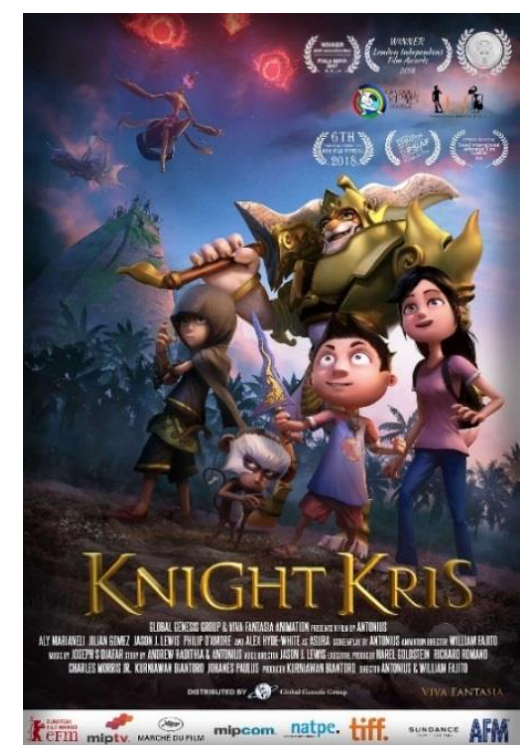

\section{Gambar 1. Poster Film Animasi Knight Kris}

Sumber: dokumentasi pribadi

Representasi budaya Jawa pada film Animasi Knight Kris akan dianalisis melalui beberapa scene yang dipilih untuk bisa menjawab rumusan masalah. Diantaranya mengenai simbol-simbol yang muncul dalam representasi budaya Jawa. Analisis hubungan beragam kode yang muncul dalam setiap level analisis film yang telah ditentukan tersebut akan menggunakan studi semiotik Peirce.

Analisis tersebut meliputi tiga level, yaitu level realitas (reality), level representasi (representation), dan level ideologi (ideology). Analisis yang dilakukan secara garis besar meliputi kondisi lingkungan, karakter, adegan, editing camera, dan semua kode lain yang dianggap sebagai kode budaya yang ditangkap secara elektronik melalui kode-kode teknis. 


\section{Level Realita (Reality)}

Asura adalah raksasa jahat yang digambarkan dalam film Knight Kris menyerupai sosok Batara Kala dalam pewayangan Jawa. Awalnya Asura adalah seorang pangeran dari sebuah kerajaan, namun karena ketamakannya yang ingin menguasai dunia, dia mempelajari semua kekuatan jahat yang ada di seluruh penjuru, hal tersebutlah yang mengubah Asura menjadi seorang raksasa yaitu Asura murka.

Para kesatria tidak tinggal diam, mereka mengumpulkan kekuatan untuk mengalahkan Asura, langkah satu satunya adalah menyatukan kekuatan dari keenam kesatria dalam sebuah keris, yang nantinya keris tersebut harus ditancapkan dikepala Asura.

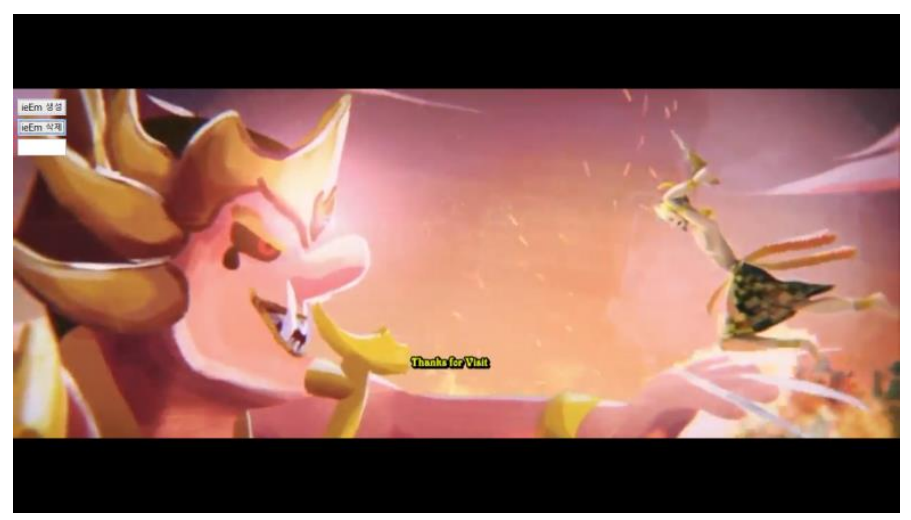

Gambar 2. Kesatria melawan Asura

Sumber : dokumentasi pribadi

A. Sign : Kekalahan Asura

B. Object : Pertempuran kesatria melawan Asura

1. Ikon: Asura melakukan serangan hebat dan mengerahkan semua pasukannya untuk menguasai seluruh makhluk di dunia. Para kesatria tidak tinggal diam, mereka membuat keris sakti untuk menahlukkan Asura, usaha para kesatria berhasil dan Asura berhasil dilumpuhkan hingga menjadi batu, kemudian Asura yang membatu ditutup oleh candi agar tidak ada penduduk yang mengetahui sosok Asura.

2. Indeks: Dari potongan adegan yang ditampilkan, tampak wajah Asura yang terlihat sangat besar dibandingkan dengan kesatria yang tengah melompat hendak menancapkan keris ke kepala Asura. Melalui kedua ikon tersebut, 
mengindekskan bahwa sedang terjadi pertempuran, dimana Asura dikalahkan menggunakan keris yang telah diberi kekuatan oleh ke-enam kesatria.

3. Simbol: Kerjasama dan kegigihan para kesatria dapat mengalahkan Asura.

C. Interpretan: Sekuat apapun Asura masih terdapat kekuatan lain yang dapat menandinginya, seperti peribahasa diatas langit masih ada langit, begitu pula para kesatria yang berusaha dengan sekuat tenaga untuk menandingi kekuatan Asura, dan berkat kerjasama antar kesatria mereka dapat menciptakan keris yang menggabungkan semua kekuatan kesatria untuk mengalahkan Asura, usaha mereka berbuah hasil, kekuatan jahat dapat dikalahkan dengan kebaikan.

\section{Level Representasi (Representation)}

Penyerangan kesatria terhadap Asura murka terdapat pada prolog yang menceritakan dengan mengulas masa lalu sehingga editing kamera menggunakan gambaran sederhana yang hanya berbentuk gambar yang digerakkan, terkesan patah patah. Seringnya menggunakan teknik zoom in untuk menegaskan ekspresi setiap karakter yaitu Asura dan Kesatria.

Latar musik yang digunakan adalah suara gending Jawa, jeritan masyarakat juga musik latar yang memberi kesan sebuah pertarungan atau peperangan, selain latar musik juga terdapat suara latar yang menceritakan kejadian tersebut. Sehingga pada adegan penyerangan Asura disajikan dengan teknik Storytelling.

Pencahayaan pada adegan ini banyak mengeluarkan unsur api karena memperlihatkan sebuah pertarungan hebat sedang terjadi, banyak unsur cahaya yang digunakan untuk memperkuat karakter. Pada saat seorang pangeran akan berubah menjadi Asura, dibagian latar terdapat cahaya yang memancar yang membuat Asura terlihat sangat kuat, begitu pula ketika adegan pangeran menancapkan keris pada kepala Asura, terdapat cahaya yang menyorot keluar dari tempat keris ditancapkan.

\section{Level Ideologi (Ideology)}

Knight Kris merupakan sebuah film yang memiliki banyak pesan tersirat. Sekilas hanyalah tentang perjalanan seorang anak bernama Bayu bersama keris 
kesatrianya, namun setiap scene yang ditampilkan banyak ngandung unsur ideologi, khususnya ideologi Jawa yang meliputi nilai-nilai keluhuran dan tata paugeraning urip (cara yang dilakukan untuk menjaga hidup). Bayu adalah anak yang pandai dan kritis, ketika Rani datang dan menyapa Bayu tanpa mengetuk pintu terlebih dahulu, dia mengingatkan Rani akan sopan santun atau adab bertamu. Sikap Rani yang mau menerima kritikan dari Bayu merupakan cerminan dari tata Paugeraning urip bagian Tresno marang sedoyo kawulo mudo.

Ketika Bayu bersikeras untuk memenuhi tantangan dari si Botak, Rani mencoba untuk mengingatkan Bayu untuk tetap bekti marang wong tuwo. Artinya dalam keadaan apapun seorang anak harus tetap berbakti kepada orang tua. Bukan hanya menolong atau menghormati orang tua, tetapi juga mematuhi apa yang mereka katakan. Bayu tetap bersikeras untuk memenuhi tantangan Botak hingga terjadilah mala petaka yang membangkitkan Asura si Raja kegelapan Rengka. Kegelapan mulai bangkit dan memporak-porandakan kampung halaman Bayu hingga mengutuk semua penduduk menjadi batu.

Bayu menyesali telah mencabut keris kesatria yang mengutuk Asura menjadi batu, sehingga sekarang Asura terbebas dan menyakiti semua penduduk. Bayu menangis dan membuang keris tersebut, hingga muncullah Empu Tandra. Seorang kesatria penjaga hutan larangan yang menjelma menjadi seekor monyet. Empu Tandra menunggu menjaga hutan larangan hingga tiba saat titisan kesatria terlahir kembali yaitu Bayu. Kesetiaan empu Tandra mencerminkan nilai Ketanggung Jawaban Sejati, yaitu mampu bertanggung Jawab dalam mengemban setiap posisinya dan berjuang hingga akhir.

Empu Tandra adalah sosok tauladan bagi Bayu. Empu Tandra memiliki sifat yang mengandung Nilai Kebijaksanaan Sejati, yaitu sifat seorang pemimpin yang selalu berusaha untuk menggunakan akal budinya atau pengalaman dan pengetahuannya secara hati-hati, cermat, dan teliti dalam mengambil setiap keputusan. Selain itu Bayu juga memiliki nilai keagungan sejati, yaitu selalu berusaha menjadi manusia yang berjiwa besar, mulia, dan luhur.

Bayu adalah tokoh utama yang menjadi penyebab sekaligus penyelamat dari ancaman kegelapan Asura. Dia ditakdirkan menjadi titisan kesatria yang akan mengalahkan Asura. Bayu memiliki sifat yang tresno marang sepadaning 
manungso. Selain itu Bayu juga memiliki sifat yang mengandung beberapa nilainilai keluhuran, diantaranya adalah nilai kesucian sejati, keyakinan sejati, kasih sayang sejati, serta nilai kebahagiaan, kedamaian, kesejahteraan dan kesentausaan sejati.

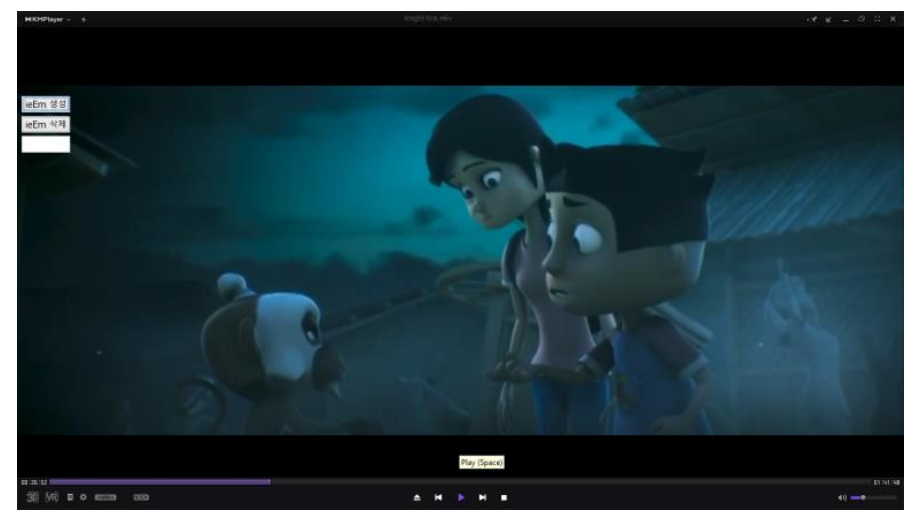

Gambar 3. Kemunculan Empu Tandra

Sumber : dokumentasi pribadi

Nilai-nilai tersebut tercermin pada setiap perilaku Bayu. Keyakinan dan kasih sayang sejati ditunjukkan ketika Bayu membela kebenaran namun tetap peduli terhadap keselamatan temannya. Sedangkan nilai kebahagiaan, kedamaian, kesejahteraan dan kesentausaan sejati dilakukan Bayu dengan cara berjuang dijalan yang benar untuk membebaskan semua orang terutama penduduk kampung dari kejahatan Asura. Yang terakhir adalah nilai kesucian sejati, Bayu berusaha membentuk dirinya menjadi manusia yang suci dan membantu masyarakat untuk menciptakan kehidupan yang suci pula. Sehingga kedamaian bukan hanya untuk dirinya, namun juga untuk semua orang.

\section{SIMPULAN DAN SARAN}

\section{Simpulan}

Representasi budaya Jawa yang diungkap dalam film Knight Kris meliputi suara, visual dan adegan. Suara terdiri dari dialog dan musik latar, visual terdiri dari karakter, latar (setting), dan properti, sedangkan adegan terdiri dari peran dan cerita. Pada film ini terdapat beberapa ikon dan properti yang merepresentasikan Budaya Jawa, seperti penggunaan caping dan cangkul yang memiliki makna etos kerja masyarakat Jawa yang dikenal sangat gigih dan rajin bekerja. Begitu juga 
dengan penggunaan keris sebagai senjata utama dalam film yang merupakan representasi senjata yang berasal dari Jawa. Atribut dan aksesoris yang digunakan pada beberapa karakter dalam film animasi ini juga merepresentasikan unsur wayang Jawa, seperti aksesoris yang digunakan oleh Asura, Bayusekti, dan Nahwara. Ketiga karakter tersebut mengenakan aksesoris selayaknya penggambaran tokoh wayang. Karakter fantasi yang meliputi Asura dan Nahwara juga memiliki wujud seperti lakon dalam pewayangan Jawa. Wajah Asura berwujud seperti Betara Kala yang sama-sama bertubuh besar seperti raksasa serta memiliki watak jahat. Sedangkan Nahwara merupakan perwujudan dari Rahwana yang karakternya menyerupai wayang topeng asli dari Jawa.

\section{Saran}

Budaya Jawa memandang manusia sebagai makhluk sosial yang memiliki cara untuk menjaga hidup sebagai tata paugeraning urip. Pemaparan hasil analisis tersebut menegaskan bahwa selain properti yang digunakan, dalam film animasi ini juga terkandung representasi budaya Jawa yang meliputi nilai keluhuran dan tata paugeraning urip. Representasi budaya Jawa dalam film animasi Knight Kris dihadirkan dalam adegan-adegan dan penokohan, hal tersebut menjadi sebuah upaya dalam mengenalkan budaya Jawa melalui media populer. Penelitian ini dapat dikembangkan dengan melakukan studi pada respon audience terhadap film animasi Knight Kris untuk mengetahui secara detail tingkat pemahaman dan tingkat penyerapan terhadap representasi budaya Jawa yang dihadirkan dalam film animasi tersebut.

\section{DAFTAR PUSTAKA}

Danesi, Marcel. 2010. Semiotika Media, Yogyakarta: Jalasutra.

Endraswara, Suwardi. 2015. Etnologi Jawa: Penelitian, perbandingan, dan Pemaknaan Budaya. Yogyakarta: CAPS

Gunarsa, Singgih. 2003. Dasar dan Teori Perkembangan Anak. BPK: Gunung Mulia.

Lombard, Denys. 2008. Nusa Jawa: Silang Budaya (Batas-Batas Pembaratan). Jakarta: Gramedia Pustaka Utama 
. 2008. Nusa Jawa: Silang Budaya (Warisan Kerajaan-Kerajaan Konsentris). Jakarta: Gramedia Pustaka Utama.

Prakosa, Gatot. 2010. Pengetahuan Dasar Film Animasi Indonesia. Jakarta: Institut Kesenian Jakarta.

Purwasito, Andrik. 2003. Komunikasi Multikultural. Surakarta, Muhammadiyah: University Press.

Rusmana, Dadan. 2014. Filsafat Semiotika: Paradigma dan Metode Interpretasi Tanda dari Semiotika Struktural hingga Dekontruksi Praktis. Bandung: Pustaka Setia.

Sobur, Alex. 2002. Analisis Teks Media. Bandung: Remaja Rosdakarya. . 2003. Semiotika Komunikasi. Bandung: Remaja Rosdakarya. 